\title{
Retrograde passage of radiofrequency catheter for the endovenous ablation of the great saphenous vein: a modified technique and report of two cases
}

\author{
Cemal Kemaloğlu \\ Received: January 21, 2014 Accepted: January 14, 2015 Published online: February 10, 2015
}

This is the report of two cases who underwent a modified great saphenous vein (GSV) ablation for venous insufficiency. For two patients with venous insufficiency and GSV reflux, radiofrequency (RF) ablation was scheduled. Both patients were obese and they had a reflux time more than four seconds in erect position with Valsalva's maneuver during color duplex ultrasound (US). Puncture for the GSV below or above the knee was unable to be performed. For both patients, a successful approach to GSV was made from the saphenofemoral junction (SFJ) at the groin level and GSV was ablated from below the knee level to the SFJ by RF.

Keywords: Endovenous radiofrequency ablation; great saphenous vein; retrograde catheterization.

Radiofrequency (RF) ablation of the incompetent great saphenous vein (GSV) is an effective and widely performed method for the treatment of varicose veins. ${ }^{[1,2]}$ Surgeons perform this method usually by similar ways: puncture to GSV usually below the knee, place the introducer, push the RF catheter upwards through the introducer, and position the tip of RF catheter $1-2 \mathrm{~cm}$ distally from the saphenofemoral junction (SFJ). What if the puncture of the GSV is unable to be performed due to various reasons such as obesity, thin GSV diameter, multiple punctures, and bleeding from the GSV or serious venospasm? This is a report of a solution for failures to enter the distal part of the GSV.

\section{CASE REPORT}

Case 1- A 42-year-old female patient was admitted due to visible varicose veins, night cramps, edema, and pain on the right leg for six months. Physical examination was remarkable for palpable varicosities on cruris and venous congestion. The patient was morbid obese with a body mass index of $40.4 \mathrm{~kg} / \mathrm{m}^{2}$. Duplex examination showed a fivesecond reflux of the right SFJ in erect position during Valsalva's maneuver and the GSV diameter was $7 \mathrm{~mm}$ at the junction level. The GSV was divided into two branches approximately $4-5 \mathrm{~cm}$ distal of the SFJ. The anterolateral branch of GSV, which was $2 \mathrm{~mm}$, showed no significant reflux. However, posteromedial branch was $5.5 \mathrm{~mm}$ with a significant reflux. Radiofrequency ablation (VNUS
ClosureFAST) for GSV and posteromedial branch was scheduled.

After initial preparation, under local anesthesia and ultrasound guidance, GSV puncture was tried below the knee level (at this level GSV diameter was $4 \mathrm{~mm}$ ). Due to thick subcutaneous adipose tissue, it was not feasible to enter GSV, despite multi-level attempts up to $10-12 \mathrm{~cm}$ above the knee. Then, we decided to make a puncture from the groin level to the GSV downwards. Under ultrasound guidance, the guide-wire was placed (Figures 1, 2). The access point for the GSV was about $3 \mathrm{~cm}$ distal of the SFJ (Figure 3). After placing the introducer, RF catheter was pushed downwards through the introducer. However, at $13-15 \mathrm{~cm}$ distally from the junction, the RF catheter was unable to be advanced forward due to the vein valve resistance. The patient was taken to reverse Trendelenburg position, and was told to make a long Valsalva's maneuver. The RF catheter was pulled back a little and pushed down simultaneously. The catheter, then, passed downwards to below the knee level without any difficulty. Tumescent anesthetic solution was given routinely (starting from below the knee level where the tip of RF catheter was to the SFJ). The procedure was completed following ablation. The GSV was

Department of Cardiovascular Surgery, Turgutlu State Hospital, Manisa, Turkey Corresponding author: Cemal Kemaloğlu, M.D. Turgutlu Devlet Hastanesi Kalp ve Damar Cerrahisi Kliniği, 45400 Turgutlu, Manisa, Turkey. Tel: +90 505 - 8990739 e-mail: cemalkemaloglu@hotmail.com 


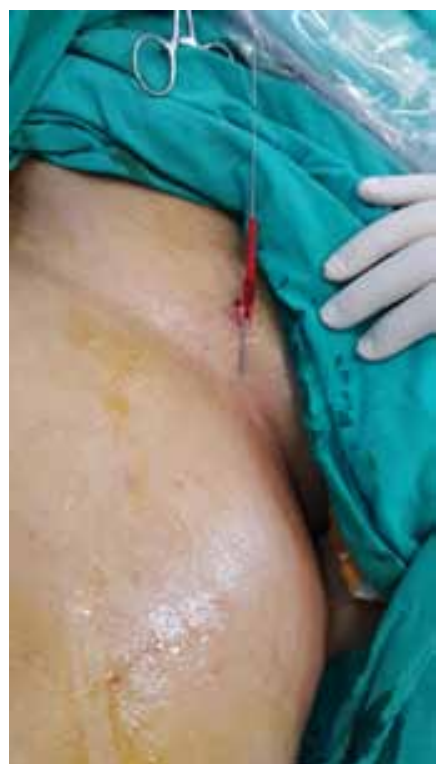

Figure 1. The retrograde puncture of the great saphenous vein on the groin level (Case 1).

completely ablated from below the knee level to the $3 \mathrm{~cm}$ distal of SFJ.

Case 2- A 51-year-old female with a weight of $88 \mathrm{~kg}$ and height of $1.59 \mathrm{~cm}$ was admitted. She was obese with a body mass index of $34.8 \mathrm{~kg} / \mathrm{m}^{2}$. She was admitted due to visible varicose veins and edema on left

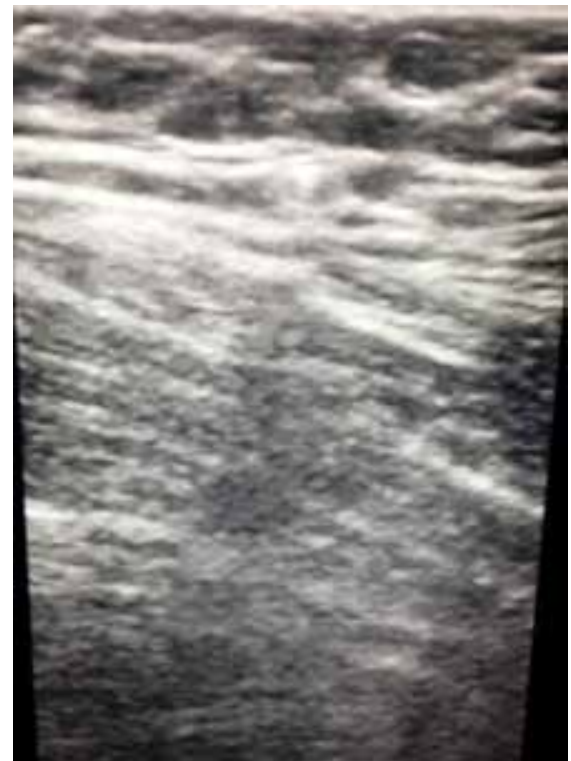

Figure 3. B-mode ultrasound view: radiofrequency catheter in great saphenous vein $3 \mathrm{~cm}$ distal of saphenofemoral junction.

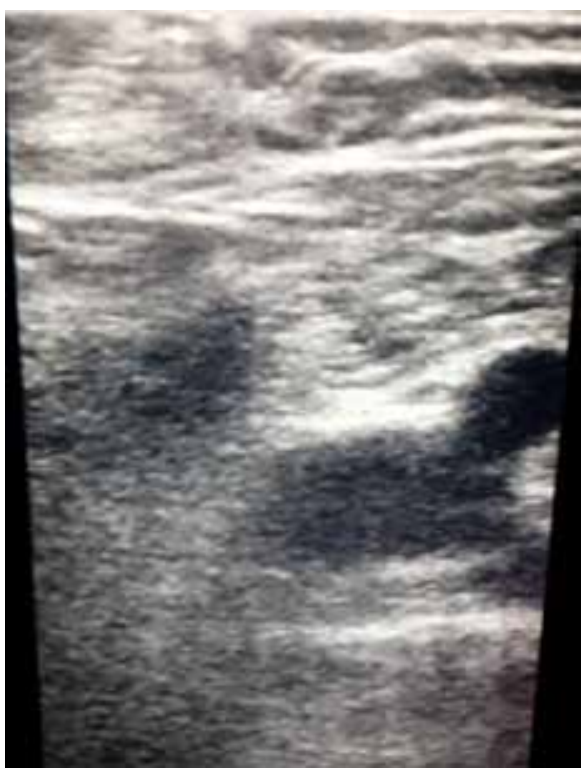

Figure 2. B-mode ultrasound view: common femoral vein, great saphenous vein, common femoral artery and guide-wire.

leg. Physical examination findings were remarkable for palpable varicosities on cruris and venous congestion. Duplex examination showed a four-second reflux of the left SFJ in erect position during Valsalva's maneuver and the GSV diameter was $6 \mathrm{~mm}$ at the junction level. Radiofrequency ablation for GSV was scheduled.

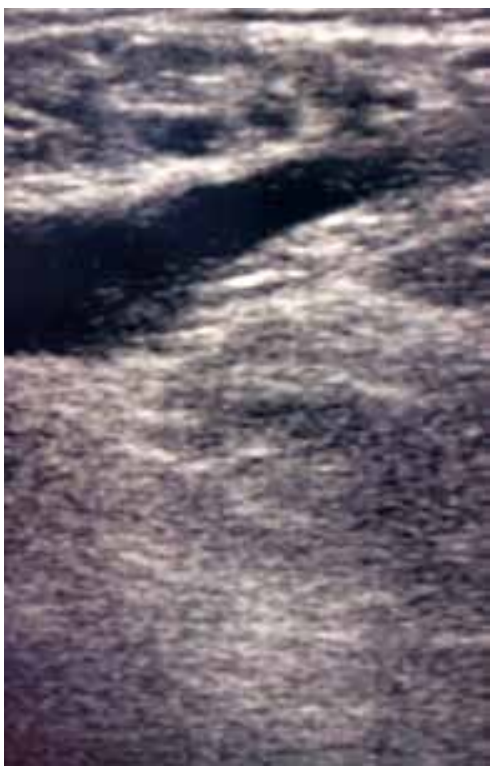

Figure 4. B-mode ultrasound view: great saphenous vein is occluded without complication, the first week control visit. 
In this case, the GSV puncture was not also feasible below the knee level, where its diameter was $3.5 \mathrm{~mm}$. The GSV was also easily cannulated downwards from the groin. The access point for the GSV was about $2 \mathrm{~cm}$ distal from the SFJ. Without any difficulty, the $\mathrm{RF}$ catheter was advanced downwards below the knee and was stuck there $(15 \mathrm{~cm}$ from the knee). After tumescent anesthetic solution was given, ablation was made and the procedure was completed.

In the first week, repeated ultrasound showed an occluded GSV without any complication (Figure 4).

\section{DISCUSSION}

Endovenous access for thermal ablation of GSV is routinely performed from below the knee level commonly. ${ }^{[3]}$ Occasionally, the puncture for GSV at this level may not be feasible due to various reasons such as obesity, thin GSV diameter, bleeding to subcutaneous tissue, and venoconstriction. All these factors may complicate the operation and force the physician for an alternative access point to GSV.

In addition, it brings several questions together when retrograde junction puncture for GSV firstly come to mind, i.e. injury of femoral vein or artery or attachment of the catheter to vein valves. In one of our cases, valve resistance occurred during the retrograde passage of the catheter, however the catheter was advanced downwards very easily with saphenous filling (reverse Trendelenburg position and Valsalva's maneuver). Puncture of GSV at the groin level was made initially under ultrasound in both patients without any arterial or venous complication.

There is a limited number of data in the literature regarding modified accesses for the GSV for thermal ablation.

In conclusion, retrograde puncture to GSV and retrograde passage of radiofrequency catheter from the groin to below the knee may be an alternative access to GSV for thermal ablation treatment.

\section{Declaration of conflicting interests}

The author declared no conflicts of interest with respect to the authorship and/or publication of this article.

\section{Funding}

The author received no financial support for the research and/or authorship of this article.

\section{REFERENCES}

1. García-Madrid C, Pastor Manrique JO, Gómez-Blasco F, Sala Planell E. Update on endovenous radio-frequency closure ablation of varicose veins. Ann Vasc Surg 2012;26:281-91.

2. Rasmussen LH, Lawaetz M, Bjoern L, Vennits B, Blemings A, Eklof B. Randomized clinical trial comparing endovenous laser ablation, radiofrequency ablation, foam sclerotherapy and surgical stripping for great saphenous varicose veins. $\mathrm{Br}$ J Surg 2011;98:1079-87.

3. Golbasi I, Turkay C, Erbasan O, Kemaloğlu C, Sanli S, Turkay M, et al. Endovenous laser with miniphlebectomy for treatment of varicose veins and effect of different levels of laser energy on recanalization. A single center experience. Lasers Med Sci 2015;30:103-8. 